\title{
INFANTILE METACHROMATIC LEUCODYSTROPHY
}

\author{
BY \\ J. W. BLACK and J. N. CUMINGS \\ From the Department of Pathology, University of Edinburgh, and the Department of Chemical Pathology, \\ Institute of Neurology, the National Hospital, Queen Square, London
}

Metachromatic leucodystrophy is an uncommon type of diffuse cerebral sclerosis. This condition is found at various ages, but it is convenient to classify cases into congenital, infantile, juvenile, and adult varieties. The infantile form, which presents a fairly constant clinical and pathological pattern, was first described by Greenfield (1933) who recorded two cases, and four further examples were reported by Russell Brain and Greenfield (1950). Jervis (1960) found 10 cases in the literature with pathological observations and described two more. To these should be added one recorded by Jacobi (1947) in which metachromasia was subsequently demonstrated by Diezel (1957), and another briefly reported by Peiffer and Hirsch (1955). Other cases have recently been described by Norman, Urich, and Tingey (1960) and by Hagberg, Sourander, Svennerholm, and Voss (1960). This report describes the pathological and biochemical observations made in a further case.

\section{Case Report}

Clinical History.-The patient, a first child, was a full-term female born normally, after an uneventful pregnancy, to healthy parents. She developed normally and walked at 13 months. There were no illnesses of note until, at the age of 22 months, a tendency to stumble and fall appeared insidiously. This became progressively worse, clumsiness of upper limb movements developed, and she became incontinent. No convulsions were observed at this stage and there was no complaint of headache. When first seen in hospital at the age of 28 months, her gait was markedly ataxic, the limb muscles being hypertonic with exaggerated tendon reflexes, bilateral knee clonus and bilateral extensor plantar responses. In addition, there was incoordination of upper limb movements and fine horizontal nystagmus, but sensation appeared to be normal. Her speech was dysarthric and dysphonic with very slow articulation. Frequent extensor spasms were observed. There was no evidence of raised intracranial pressure and the fundi appeared normal. Physical examination was otherwise negative. The protein content of the cerebrospinal fluid was slightly elevated on two occasions at $60 \mathrm{mg}$. per $100 \mathrm{ml}$. and $50 \mathrm{mg}$. per $100 \mathrm{ml}$., but the cell count was not raised. The Wassermann reaction was negative and the Lange curve normal. As the patient's aunt suffered from hepatolenticular degeneration, investigations of copper metabolism were undertaken and this diagnosis excluded. Other biochemical and bacteriological investigations were negative, radiological examinations were not helpful, and two electro-encephalograms were reported as showing no significant abnormalities.

The diagnosis was thought to be diffuse sclerosis and no treatment was undertaken. Within two months the child was unable to walk, while a month later she could sit only with support. Her speech became more indistinct with a contracted vocabulary. Finally, she became unconscious in a state of decerebrate rigidity with numerous, severe convulsions which required continuous sedation with phenobarbitone. She died at the age of 34 months, the illness having lasted for one year. A sibling was alive and well at the age of 15 months.

Post-mortem Examination.-This was carried out by Dr. A. D. Bain within 12 hours of death. The body was that of a wasted female child showing no other external abnormalities. The gall bladder wall was moderately thickened and its lumen was filled by a pale grey papilloma. There was moderate tracheo-bronchitis but no pneumonia and the remaining viscera showed no macroscopic abnormalities. The skull, dura mater, and venous sinuses were normal. The brain, which weighed $1,000 \mathrm{~g}$., and spinal cord were examined after fixation in $10 \%$ formalin. Apart from slight congestion of the cerebral leptomeninges, no external abnormality was noted. On section the cortical grey matter showed no unusual features. The white matter of the cerebrum, brain-stem, and cerebellum was firmer than usual and had a bleached appearance. Pallor of the thalami was seen and there was slight dilatation of the third ventricle. The spinal cord was firmer than usual but was of normal appearance externally and on section.

Histology of the Nervous System.-Paraffin-embedded and frozen sections were examined by various staining methods.

Cerebral White Matter.-There is almost complete demyelination in the corpus callosum, centrum semiovale, and convolutional white matter without sparing of the arcuate fibres, the optic tracts and radiations being less 
severely affected. Surviving myelin sheaths are swollen, beaded, and fragmented. A reduction in the number of axis cylinders is evident, some interrupted fibres showing end bulbs. Loss of oligodendroglia is seen, paralleling the severity of demyelination. A moderate rod cell reaction is present but there are few neutral fat-containing foam cells and these are confined almost entirely to perivascular spaces. Fairly marked astrocytic proliferation is present throughout, binucleate and gemästete forms being seen, with dense, diffuse, fine, fibrillary gliosis (Fig. 1). Much metachromatic material is found in the demyelinated areas, largely within distended histiocytes. Smaller masses are seen lying free between glial fibrils, and some gemästete astrocytes contain, or show, surface encrustation by the same material (Fig. 2).

Cerebral Cortex.-The architecture is well preserved and most neurones appear normal, but in the deepest layers of the cortex a few are slightly swollen and contain intracytoplasmic metachromatic granules, usually with peripheral displacement of the nucleus. A few others show apparent encrustation of their surface and small aggregates of metachromatic material are seen lying free. Microglial and astrocytic proliferation accompany these changes.

Basal Ganglia.-Essentially similar changes are present here and metachromatic material is seen not only in the main white matter tracts but also, to a lesser extent throughout the grey matter masses in relation to traversing fibres. There is relative sparing of the ansa lenticularis (Fig. 3). Diffuse gliosis is present, particularly in the thalamus and a few neurones contain metachromatic material.

Brain-stem.-Severe demyelination is seen in the bases pedunculi and pyramids, the histological features being identical with those already described in the cerebral white matter. The spinocerebellar tracts are spared to a great extent; the superior, middle, and inferior cerebellar peduncles; the medial lemnisci; the medial longitudinal fasciculi; the tectospinal tracts, and the fibres emerging from the hilum of each inferior olive (Fig. 4). Oligodendroglial nuclei are seen in these tracts, though possibly in slightly reduced numbers. Many examples of neurones with intracytoplasmic metachromatic granules are found in the brain-stem, particularly in cranial nerve nuclei in the medulla but also, to a lesser extent, in the inferior olives and pontine nuclei.

Cerebellum.-The white matter shows similar features to that of the cerebrum. There is a possible slight deficiency of the granular cell layer. Patchy loss of Purkinje cells is evident, associated with proliferation of Bergmann astrocytes and isomorphous, fibrillary gliosis in the molecular layer. Little metachromatic material is present in the granular layer and none is seen in Purkinje cells or in the molecular layer. In contrast, all the neurones of the dentate nucleus contain many metachromatic granules and rod cell proliferation with gliosis is present here (Fig. 5).

Spinal Cord.-There is partial demyelination of the lateral and, to a lesser extent, anterior columns accompanied by fibrillary gliosis (Fig. 6). Many oligodendroglial nuclei persist in the affected tracts and only occasional metachromatic granules are seen. Some neurones of both the anterior and posterior horns conta星 the material and it is present also in partially demyelinated anterior nerve roots.

Cranial Nerves.-The olfactory tracts are only sligh involved. Myelination is well preserved in the opte nerves, but on passing backwards through the chiasma the fibres show progressively increasing damage. Other cranial nerves examined are patchily demyelinated apd contain metachromatic material.

Throughout the central nervous system the lept:meninges and vessels are normal.

Peripheral Nerves. - No intact nerves were availabite for examination, but small granules of metachromatip material are seen in autonomic nerves in a heapt section.

Staining and Other Properties of the Granular Materi -Frozen sections were stained with thionin or toluidine blue, according to the methods described by Leslie (1952), passed rapidly through graded alcohols and mounted in mersol. These preparations faded rapidly and more permanent results were obtained with cresyl violet using the method employed by Hirsch and Peiffer (1957). Wi ih thionin, the granules stain a reddish-brown cologr initially, but dehydration results in a change, first toza dull olive green and then to a brilliant emerald greeis. With toluidine blue the material exhibits purple meta chromasia, while the cresyl violet a rich golden-brown colour is obtained. No metachromasia can be dergots strated in paraffin sections.

Lipid.-The granular material stains very faintly or: with Scharlach $R$ in frozen sections. Sudan black stains it brown in paraffin sections and dark brown m frozen sections. Nile blue sulphate results in blue staigiag of the material in frozen sections.

Effect of Lipid Solvents.-Frozen sections, after timg taken rapidly through the alcohols were left for 18 tus at room temperature in a variety of common solvents. They were then taken down to water and stained by the cresyl violet method. Metachromasia is completely lost after exposure to chloroform or pyridine, while xylol benzene result in considerable diminution. Seventy-fige per cent or absolute alcohol, acetone, or ether produge moderate loss.

Carbohydrates.-The periodic-acid-Schiff (P.A. method stains the granules reddish-purple, more inten in frozen than paraffin sections. The material stains pin with Southgate's mucicarmine in both frozen and parafin sections, and positively with alcian green.

Optical Activity.-In frozen sections only, some of the granules are birefringent.

Other Staining Reactions.-With Heidenhain's azån some of the granules stain blue and others are red, both being seen within the same aggregate or neurone. Bluestaining granules predominate in paraffin sections, red frozen material. Similar, but sharper, differential staini@g is obtained using Lendrum's acid picro-Mallory method. The granules are eosinophilic and phloxinophilic; they stain dark blue with Mallory's phosphotungstic acta haematoxylin, dark grey with myelin stains and Hortegefs method for axis cylinders, and pink with Cajal's gold sublimate. 


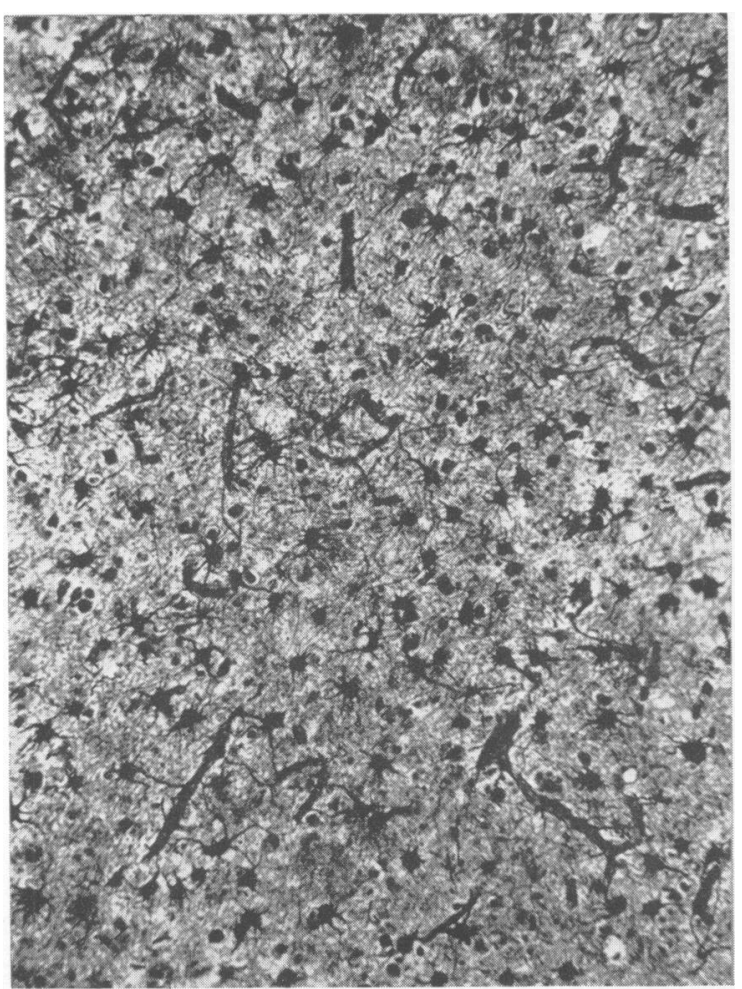

FIG. 1.-Cerebral white matter. Astrocytic proliferation. Cajal $\times$ 135.

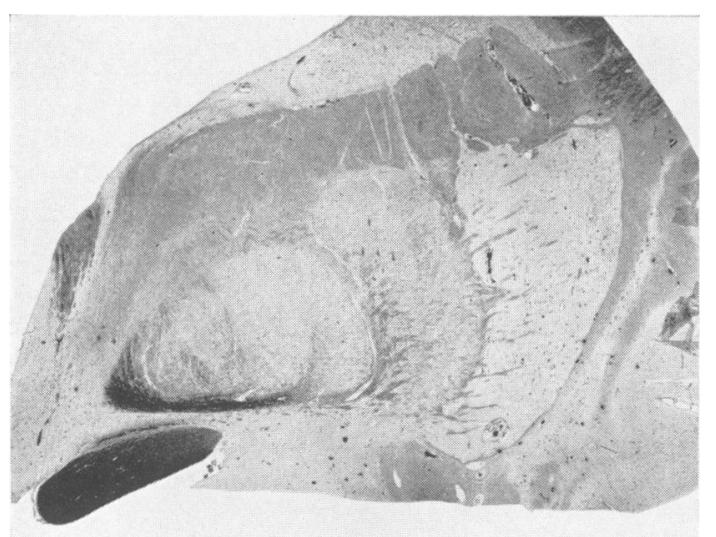

FIG. 3.-Basal ganglion showing demyelination with relative sparing of the optic tract and ansa lenticularis. Loyez $\times 2$.

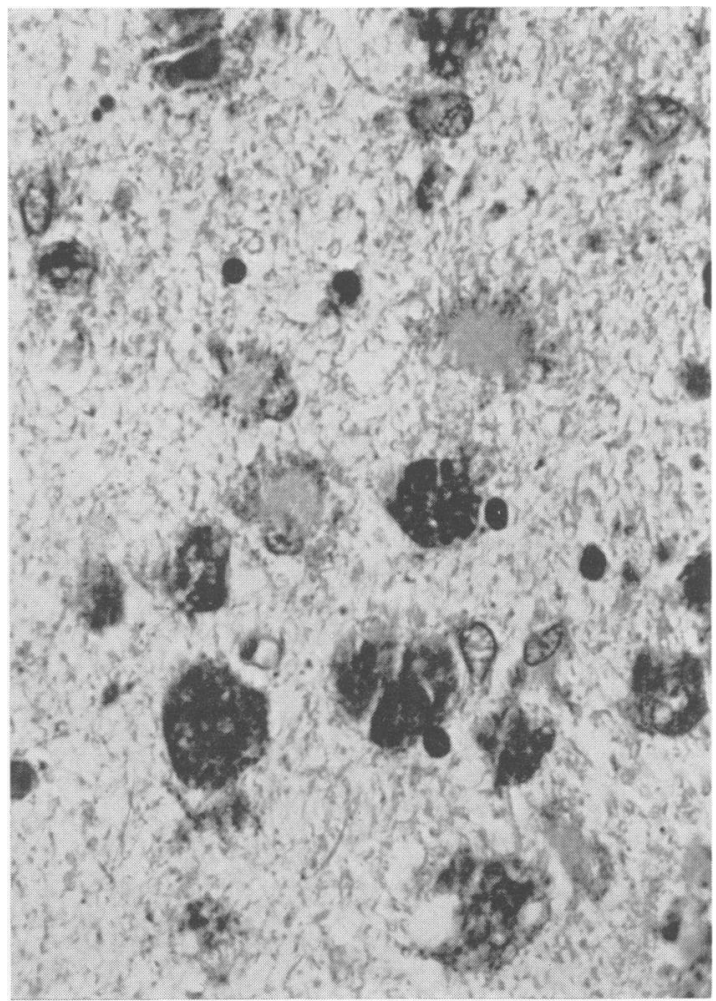

FIG. 2.-Cerebral white matter. Granular material within histiocytes and encrusting gemästete astrocytes. P.A.S. $\times 700$.

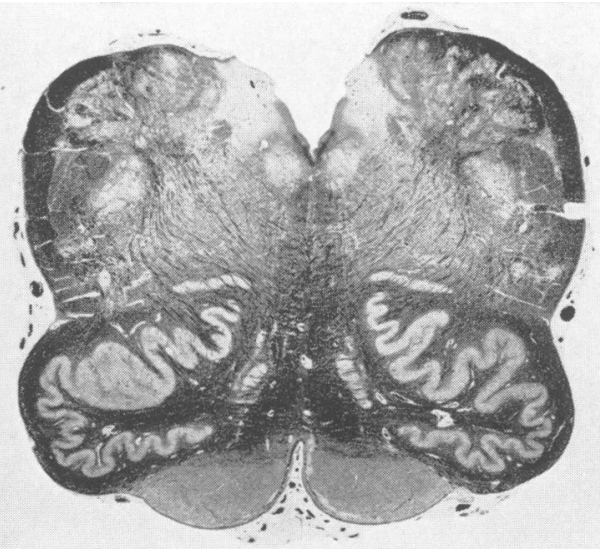

Fig. 4.- Medulla. Note preservation of many tracts and demyelination of pyramids. Loyez $\times 3$. 


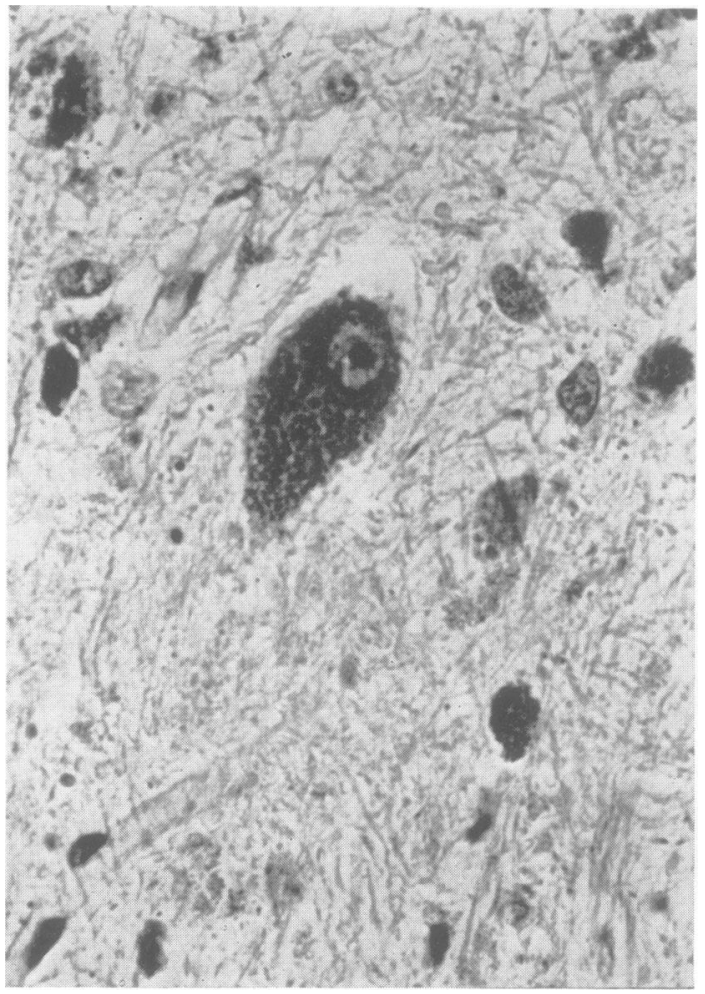

Fig. 5.-Dentate nucleus. Neurone distended with granular material. P.A.S. $\times 700$.

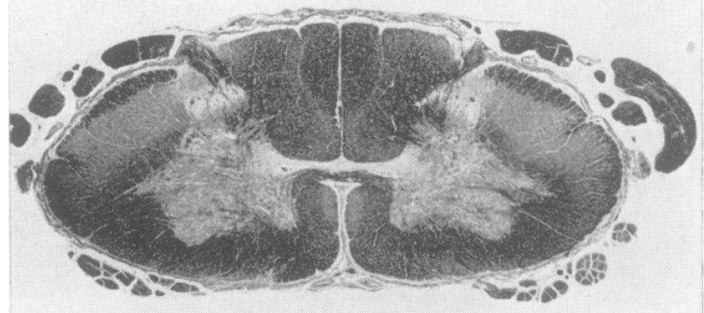

FIG. 6. - Spinal cord. Demyelination of lateral columns. Loyez $\times 3 \frac{1}{2}$.

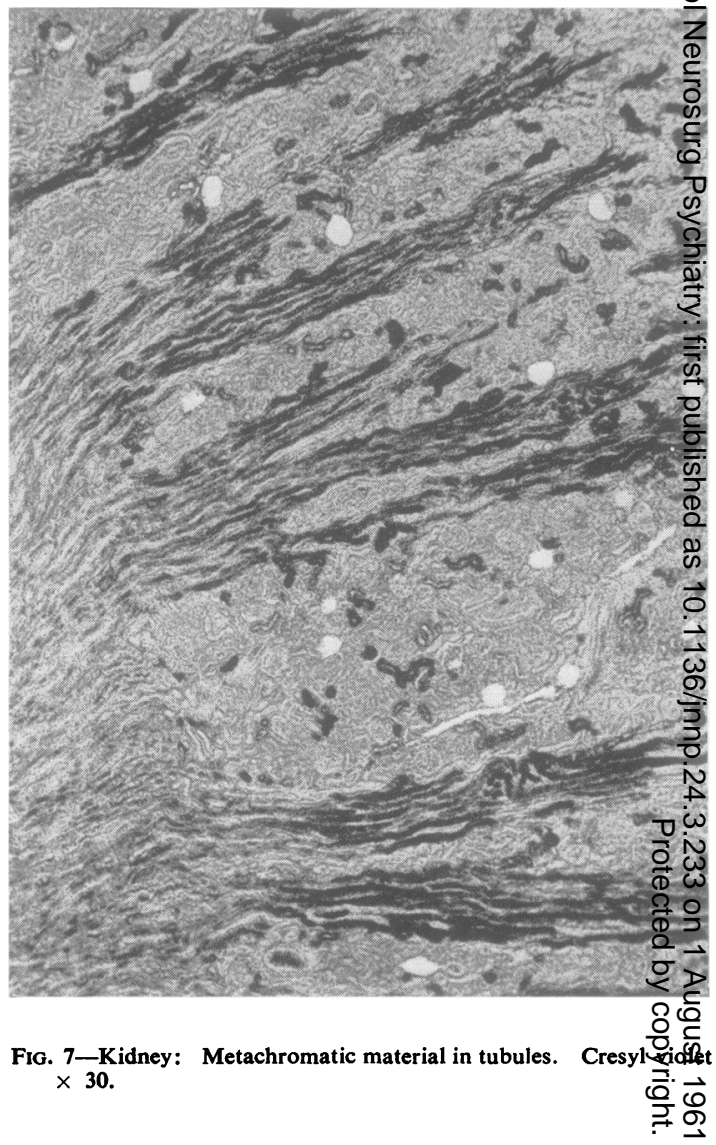

Histology of the Viscera.-In frozen sections of the kidneys large quantities of metachromatic material ame seen in the slightly swollen epithelial cells of convoluted tubules (probably the distal), both limbs of Henle's logp and in collecting tubules (Fig. 7). Smaller amounts are present within the lumen of tubules but the glomeruli fte normal. The affected cells stain poorly with eosin gr P.A.S. in paraffin sections. The gall bladder papilloma is composed of a highly branched, vascular, connect tissue stroma covered by columnar epithelial cells which contain large amounts of metachromatic material. Tis is also present within histiocytes in the connective tissue stroma. Small quantities of similar material are seen $\bar{\phi}$ histiocytes in the portal tracts of the liver. Other organs examined contain no metachromatic material and की normal, apart from the lungs which show the ustal feature of acute bronchitis and bronchiolitis.

Biochemical Studies.-Representative portions of the formalin-fixed brain and kidney were examined for various lipids, utilizing for their extraction the proceduree of Folch, Lees, and Sloane-Stanley (1957a) using a 2:1 chloroform-methanol solvent $(\mathrm{v} / \mathrm{v})$. Water content, total phospholipid, total and free cholesterol were determinged 
as in previous examinations (Cumings, 1953). Hexosamine and neuraminic acid (gangliosides) were estimated (Cumings, 1957) as well as neutral cerebrosides (Radin, Lavin, and Brown, 1955). Cerebron sulphuric acid was estimated as barium sulphatides by the method of Radin, Martin, and Brown (1957), using the formula of Folch et al. (1957b). The galactose fraction of the barium sulphatide can be estimated by a suitable anthrone procedure and this has also been done and has given similar or identical results to the gravimetric procedure. The hexosamine fractions-lipid-soluble, water-soluble, and residualhave also been determined by methods similar to those of a previous report (Cumings, Goodwin, and Curzon, 1959). The results of these examinations can be seen in Table I.

TABLE I

CEREBRAL LIPIDS IN THE BRAIN

\begin{tabular}{|c|c|c|c|c|}
\hline \multirow{2}{*}{ Substance } & \multicolumn{2}{|c|}{$\begin{array}{l}\text { Cerebral White } \\
\text { Matter }\end{array}$} & \multicolumn{2}{|c|}{ Cerebral Cortex } \\
\hline & Patient & Normal & Patient & Normal \\
\hline $\begin{array}{l}\text { Total phospholipid } \\
\text { Total cholesterol } \\
\text { Esterified cholesterol } \\
\text { Neutral cerebrosides } \\
\text { Ganglioside } \\
\text { Lipid-soluble hexosamine } \\
\text { Water-soluble hexosamine } \\
\text { Residual hexosamine } \\
\text { Sulphatide } \\
\text { Water }(\%)\end{array}$ & $\begin{array}{c}10.71 \\
9.43 \\
0.08 \\
6.36 \\
0.05 \\
0.05 \\
0.54 \\
2.7 \\
78.9\end{array}$ & $\begin{array}{c}20 \cdot 1 \\
13 \cdot 1 \\
0 \cdot 4 \\
7 \cdot 14 \\
\overline{0.04} \\
0 \cdot 02 \\
0 \cdot 35 \\
1.9 \\
75 \cdot 7\end{array}$ & 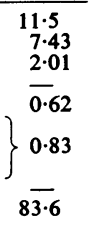 & 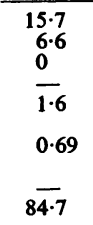 \\
\hline
\end{tabular}

Results in g./100 g. dry tissue.

There is seen to be a well-marked loss of total phospholipid and of total cholesterol in the white matter with a slight loss of phospholipid in the cortex. Esterified cholesterol is present to an amount greater than the normal in the cortex but not in the white matter. Neutral cerebrosides in the white matter and gangliosides in the cortex are both reduced in amount. Total hexosamine in the cerebral white matter is increased, and this increase is due to a greater amount of residual hexosamine, for both the lipid-soluble and the water-soluble hexosamine fractions are within normal limits. These findings are similar to those previously described in post-mortem material (Cumings, 1957, 1960a, 1961). There is also a greater amount of sulphatide in the white matter than is present normally even though the tissue had been fixed in formalin for some months, and this is similar to the findings on other cases already reported at the London Conference on the Scientific Study of Mental Retardation in 1960 (see Cumings, 1961).

The sulphatide content in the kidney was $0.4 \mathrm{~g}$. per $100 \mathrm{~g}$. dry tissue and this is not raised to any appreciable extent as compared with the figures quoted by Austin (1960) for his normal controls, but at present there are no figures available for such controls using the method employed here.

\section{Discussion}

The clinical features observed in this case are very similar to those of other recorded examples except for the cerebrospinal fluid protein content, which in almost all has exceeded $100 \mathrm{mg}$. per $100 \mathrm{ml}$. Jefferson (1958) reported electro-encephalographic changes which he thought might prove of diagnostic value but these were not confirmed by Jervis (1960) nor in the present case.

Pathologically, all cases show diffuse demyelination, complete in some while in others, including this example, there has been comparative sparing of certain tracts. In general, as Russell Brain and Greenfield (1950) pointed out, the preserved pathways tend to be those which are myelinated at or shortly after birth. Neutral lipid is almost entirely absent and the striking feature is the presence of metachromatic material either lying free or within proliferated glial cells. In the literature, there is controversy as to whether microglia or astrocytes are involved, but in this case, as in those of Jervis (1960), both are implicated. The behaviour of the oligodendroglia is variable. Russell Brain and Greenfield (1950) emphasized their disappearance or considerable reduction not only in demyelinated areas, but also in well-preserved tracts, and they considered this to be evidence for a primary disorder of oligodendroglia. Similar observations have been made in some recorded cases while in others, including the present one, oligodendroglial loss has parallelled the severity of demyelination. Jervis (1960) found that they were irregularly involved and saw many areas with no evident decrease. Lumsden (1951) suggested that an enzymatic abnormality of the oligodendroglia resulted in abnormal myelin metabolism and accumulation of the metachromatic lipid which normally appears briefly as a catabolic product. Diezel (1957) agreed with this view, without specifically implicating the oligodendroglia. On the other hand, Feigin (1954) described the case of an infant dying a few weeks after a premature delivery and pointed out that as very little myelin could have been present at birth, the metachromatic material was unlikely to have been derived from its breakdown.

In almost all reported cases metachromatic material has been observed within the cytoplasm of neurones, particularly in the dentate and brain-stem nuclei. The affected cells are distended and the nucleus is displaced peripherally, producing a resemblance to the neurones seen in amaurotic family idiocy and other cerebral lipidoses. This observation led Norman (1947) to the conclusion that metachromatic leucodystrophy should be regarded as closely related to the lipid storage disorders and he commented that demyelination occurs in these, while in no other demyelinating condition are catabolic products found in neurones. His views, later endorsed by Hirsch and Peiffer (1957), by Edgar (1957), and by others, represent the current opinion on the nature of the disease. 
Metachromatic material in other organs, particularly the kidneys, liver, and gall bladder, where papilloma formation has been described (Norman, 1947), has been noted in several cases, but it remains uncertain whether this is evidence of a generalized disorder or merely an indication of excretion of the material. Certainly the visceral deposits in the present case, as Russell Brain and Greenfield (1950) also found, do not appear to be histochemically identical with those in the nervous system.

Extensive histochemical studies of the metachromatic material in cases from various age groups have been carried out by Diezel (1957) and by Hirsch and Peiffer (1957) in addition to observations reported in individual examples. Even allowing for technical variations, conflicting results have been obtained (Feigin, 1954). Thus, the material stained positively with techniques for mucin and related substances in our case and in those of Russell Brain and Greenfield (1950) and of Hain and LaVeck (1958), whereas Leslie (1952), Norman et al. (1960) and Jervis (1960) reported it to be negative. Furthermore, although metachromasia is lost in paraffinembedded tissue, positive staining with P.A.S. is retained, pointing to at least two compounds being present. This view is reinforced by the ability to obtain differential staining of the granules, a feature also found by Russell Brain and Greenfield (1950), by Leslie (1952), and by Bertrand, Thieffry, and Bargeton (1954). Certain properties are common to most cases. The material is acid, P.A.S. positive, and stains with Sudan black B and Nile blue sulphate but only faintly with Scharlach $\mathbf{R}$. There is general agreement that it is a glycolipid, and Diezel (1957) showed that it was not identical histochemically with the cerebrosides of the myelin sheath nor with the ganglioside found in distended ganglion cells in amaurotic family idiocy. The metachromatic material is almost certainly the sulphatide demonstrated chemically.

In 1957, Edgar examined formalin-fixed material from 11 cases of metachromatic leucodystrophy and found levels of lipid hexosamine raised above the normal. Cumings $(1957,1959)$ also reported on cases verified histologically which showed a raised level of total hexosamine. Blackwood and Cumings (1959) have recorded seven cases of this disease diagnosed biochemically from the raised level of total hexosamine in cerebral biopsy material and four of them were verified histologically. There are four other cases recorded, two by Cumings (1960a) and two by Tingey (1959), in all of which raised levels of total hexosamine were found. All these cases were confirmed by histological examination of necropsy material.

One of us (Cumings, 1961) has examined seven cases confirmed by necropsy and in all increase amounts of total hexosamine were found in the cerebral white matter, and in three out of fow of these cases in which the examination has been performed increased sulphatides have been found.

Jatzkewitz $(1958,1960)$ obtained some evidence of a raised content of sulphatide in the brain, mowe especially when it was calculated against the sphingolipid fraction of the cerebral lipids, but hï technique was different from that used here. Austim (1957) drew attention to the presence of metachromatic material in the urine and in 1960 further showed that there was an increase in thes amount of cerebroside sulphuric acid esters in the cerebral white matter and in the kidney. One of (J.N.C.) has found metachromatic material in the urine (Cumings, 1960b) from such patients but has also found it to be present in non-catheter specimen from young female children. The amounts off sulphatide found by Austin (1960) in normal whi matter are very similar to those found by us as we्p as by Hagberg et al. (1960) who described two cas of metachromatic leucodystrophy with raised leveds sulphatide. The results of Jervis (1960) for $\bar{\phi} u t$ phatides in his two cases are very similar to thos of Austin, Hagberg et al., and ourselves. Norman e $\vec{B} a$. (1960) have recently described two further cases and Mossakowski, Mathieson, and Cumings (1961) hage recorded three cases in one family.

The diagnosis can be made with a considerabte degree of certainty from the findings of raised lefs of total hexosamine and of sulphatides in either biopsy material or in the brains of cases examined at necropsy.

\section{Summary}

The clinical, pathological, and chemical findings in a case of infantile metachromatic leucodystrophy are described.

Metachromatic granular material had accumulated in areas of demyelination, within certain neurone्今, and in the kidney, liver, and in a papilloma of the gall bladder. Increased quantities of total hex samine and sulphatide were present in the cerebral white matter, confirming the findings in other reported cases.

The relationship of metachromatic leucodystrop to the cerebral lipidoses is discussed.

We are indebted to Dr. A. F. J. Maloney for his helpful advice, to Messrs. H. Goodwin and D. Miller for skilled technical assistance, and to the Medical Photograp Unit of the University of Edinburgh for the photograplos.

We wish to thank Drs. J. O. Forfar and G. MacNaugh ton for access to their clinical records and Dr. A. D. Baig for his necropsy report. 


\section{REFERENCES}

Austin, J. H. (1957). Neurology, 7, 415.

- (1960). Ibid, 10, 470 .

Bertrand, I., Thieffry, S., and Bargeton, E. (1954). Rev. neurol., 91, 161.

Blackwood, W., and Cumings, J. N. (1959). Lancet, $2,23$.

Brain, W. Russell, and Greenfield, J. G. (1950). Brain, 73, 291

Cumings, J. N. (1953). Ibid, 76, 551.

1957). In Cerebral Lipidoses: A Symposium, p. 112, edited by L. van Bogaert, J. N. Cumings, and A. Lowenthal, Blackwell, Oxford.

(1959). J. clin. Path., 12, 489.

(1960). In Modern Scientific Aspects of Neurology, p. 330, edited by J. N. Cumings. Arnold, London.

(1960b). Psychiat. Neurol. Neurochir. (Amst.), 63, 110.

(1961). In Proceedings of the London Conference on the Scientific Study of Mental Retardation (1960).

-- , Goodwin, H., and Curzon, G. (1959). J. Neurochem., 4, 234 edited by $L$. van Bogaert, J. N. Cumings, and A. Lowenthal, Blackwell, Oxford.

Edgar, G. W. F. (1957). Ibid, p. 186

Feigin, I. (1954). Amer. J. Path., 30, 715 .

Folch, J., Lees, M., and Sloane-Stanley, G. H. (1957a). J. biol. Chem., 226, 497. (1957b). In Metabolism of the Nervous System, p. 174, edited by D. Richter. Pergamon Press, London. Greenfield, J. G. (1933). J. Neurol. Psychopath., 13, 289, and Proc. roy. Soc. Med., 26, 690

Hagberg, B., Sourander, P., Svennerholm, L. and Voss, H. (1960). Acta paediat. (Uppsala), 49, 135.

Hain, R. F., and LaVeck, G. D. (1958). Pediatrics, 22, 1064.

Hirsch, T. von, and Peiffer, J. (1957). In Cerebral Lipidoses: A Symposium, p. 68, edited by L. van Bogaert, J. N. Cumings, and A Lowenthal. Blackwell, Oxford.

Jacobi, M. (1947). Virchows Arch. path. Anat., 314, 460

Jatzkewitz, H. (1958). Hoppe-Seylers, Z. physiol. Chem., 311, 279. (1960). Ibid, 318, 265.

Jefferson, M. (1958). Proc. roy, Soc Med. 51, 160

Jervis, G. A. (1960). J. Neuropath. exp. Neurol., 19, 323.

Leslie, D. A. (1952). J. Path. Bact., 64, 841.

Lumsden, C. E. (1951). Brit. med. J., 1, 1035.

Mossakowski, M., Mathieson, G., and Cumings, J. N. (1961). Brain, in press.

Norman, R. M. (1947). Brain, 70, 234.

- Urich, H., and Tingey, A. H. (1960) Ibid, 83, 369

Peiffer, J., and Hirsch, T. von (1955). Excerpta med. (Amst.), Sect. VIII, 8, 802.

Radin, N. S., Lavin, F. B., and Brown, J. R. (1955). J. biol. Chem., 217,789

Tingartin, F. B., and Brown, J. R. (1957). Ibid, 224, 499.

Tingey, A. (1959). J. Neurochem., 3, 230. 